\title{
Very late outcomes for mitral valve replacement with the Carpentier-Edwards pericardial bioprosthesis: 25-year follow-up of 450 implantations
}

\author{
Thierry Bourguignon, MD, ${ }^{\mathrm{a}}$ Anne-Lorraine Bouquiaux-Stablo, MD, ${ }^{\mathrm{a}}$ Claudia Loardi, MD, ${ }^{\mathrm{a}}$ \\ Alain Mirza, MD, ${ }^{a}$ Pascal Candolfi, PhD, ${ }^{b}$ Michel Marchand, MD, ${ }^{a}$ and Michel R. Aupart, MD ${ }^{\mathrm{a}}$
}

Objective: The aim of the present study was to evaluate the very-long-term results of the Carpentier-Edwards pericardial bioprosthesis in the mitral position.

\begin{abstract}
Methods: From 1984 to 2011, 450 Carpentier-Edwards PERIMOUNT pericardial mitral bioprostheses were implanted in 404 consecutive patients (mean age, 68 years; 53\% female). Patients undergoing multiple valve replacements were excluded. The clinical, operative, and follow-up data were prospectively recorded. The mean follow-up was $7.2 \pm 5.1$ years, for a total of 3258 valve-years. The follow-up data were $97.8 \%$ complete.

Results: The operative mortality rate was 3.3\%. A total of 188 late deaths occurred, for a linearized rate of $5.8 \%$ /valve-year. At 20 years, the overall actuarial survival rate was $16.9 \% \pm 3.9 \%$. Age at implantation, preoperative New York Heart Association class III or IV, and redo procedure were significant risk factors affecting late survival. The actuarial freedom from complications at 20 years was thromboembolism, $83.9 \% \pm 7.6 \%$; hemorrhage, $80.2 \% \pm 10.8 \%$; endocarditis, $94.8 \% \pm 1.4 \%$; structural valve deterioration, $23.7 \% \pm 6.9 \%$; and explantation owing to structural valve deterioration, $40.5 \% \pm 8.0 \%$. The competing risk analysis demonstrated an actual risk of explantation owing to structural valve deterioration at 20 years of $25.5 \% \pm 2.9 \%$. The expected valve durability was 16.6 years for the entire cohort $(11.4,16.6$, and 19.4 years for patients aged $<60$, 60 to 70 , and $>70$ years, respectively).
\end{abstract}

Conclusions: With a low rate of valve-related events at 20 years and, in particular, a low rate of structural valve deterioration, the Carpentier-Edwards PERIMOUNT pericardial bioprosthesis remains a reliable choice for a mitral tissue valve, especially in patients $>60$ years old. (J Thorac Cardiovasc Surg 2014;148:2004-11)

f Supplemental material is available online.

The Carpentier-Edwards PERIMOUNT bioprosthesis (Edwards Lifesciences, Irvine, Calif) is a trileaflet valve consisting of bovine pericardial leaflets mounted underneath a flexible cobalt-chromium stent. This valve was designed to minimize structural valve deterioration (SVD), which had plagued earlier generation pericardial bioprostheses, ${ }^{1,2}$ retaining the

From the Department of Cardiac Surgery, ${ }^{a}$ Trousseau University Hospital, Tours, France; and Department of Biostatistics, ${ }^{b}$ Edwards Lifesciences, Nyon, Switzerland.

Supported in part by a research grant from Edwards Lifesciences LLC, Irvine, Calif. Disclosures: Pascal Candolfi is an employee of Edwards Lifesciences and reports equity ownership. Michel Marchand reports consulting and lecture fees from Edwards Lifesciences. Michel R. Aupart reports consulting fees from Edwards Lifesciences. All other authors have nothing to disclose with regard to commercial support.

Presented in part at The American Association for Thoracic Surgery Mitral Conclave, May 2013, New York, NY

Received for publication May 31, 2013; revisions received Jan 29, 2014; accepted for publication Feb 14, 2014; available ahead of print March 22, 2014.

Address for reprints: Thierry Bourguignon, MD, Department of Cardiac Surgery, Trousseau University Hospital, 7 rue de la Scellerie, Tours 37000, France (E-mail: thierry-bourguignon@hotmail.fr).

0022-5223/\$36.00

Copyright (c) 2014 by The American Association for Thoracic Surgery

http://dx.doi.org/10.1016/j.jtcvs.2014.02.050 hemodynamic superiority conferred by pericardial valve construction relative to porcine valves. The middle-term results were promising, with a low rate of valve-related events and, especially, a low rate of deterioration. ${ }^{3,4}$

The present study reports our 25-year experience with the Carpentier-Edwards pericardial valve implanted in the mitral position starting in 1984.

\section{METHODS}

From August 1984 to March 2011, 450 Carpentier-Edwards PERIMOUNT pericardial bioprostheses were implanted in 404 consecutive patients for mitral valve replacement (MVR) in our hospital. Of the 404 patients, 46 required a second bioprosthesis and were considered as new patients with a new valve. The indications for MVR with a bioprosthesis rather than a mechanical valve were patients aged $\geq 60$ years and those who were younger if they had met specific conditions (eg, endocarditis, short anticipated life expectancy because of comorbidities, contraindication to oral anticoagulant treatment, informed patient choice). During the study period, 240 mechanical mitral valve replacements and 700 mitral valve repairs were performed; therefore, the present series concerned one third of the patients who had undergone mitral valve surgery in our department. Patients undergoing multiple valve replacement were excluded from the present study; however, no patients were excluded because of other concomitant operations. The preoperative characteristics of the cohort are listed in Table 1.

The data from all patients undergoing valve replacement at our institution since 1984 were prospectively entered into a computer database, and 

Abbreviations and Acronyms
AUC $=$ area under the curve
$\mathrm{CI}=$ confidence interval
HR = hazard ratio
MST $=$ median survival time
MVR $=$ mitral valve replacement
$\mathrm{SVD}=$ structural valve deterioration

the patients were followed up on an annual basis. In addition, yearly questionnaires were mailed to all the patients. If the questionnaires were not returned or the patient reported an adverse event, telephone or personal interviews were conducted. All patients underwent transthoracic echocardiography at the follow-up examination. For the patients who died, the Social Security Death Index was used to confirm the date.

The mean follow-up period was $7.2 \pm 5.1$ years (range, 0 to 24.8 ) for a total of 3258 valve-years. The follow-up data were complete for $97.8 \%$ of the population. The closing interval for the present study was 12 months. Morbidity and mortality were defined according to the guidelines of The Society of Thoracic Surgeons and the American Association for Thoracic Surgery. ${ }^{5,6}$

The operative techniques used were similar to those previously reported. ${ }^{7}$ The patients underwent surgery through a median sternotomy with standard cardiopulmonary bypass and moderate hypothermia $\left(32^{\circ} \mathrm{C}\right.$ $36^{\circ} \mathrm{C}$ ). Myocardial protection was accomplished using crystalloid or blood cardioplegia and topical cooling. The surgical techniques remained constant throughout the entire experience. The bioprosthesis was rinsed in saline solution and secured with simple interrupted sutures. Beginning in 1988, the subvalvular apparatus of the posterior and anterior leaflets was preserved whenever possible. The operative data are listed in Table 1.

The postoperative anticoagulant protocol changed during the study period. Before 1998, it included heparin for 2 days, followed by 1 month of calcium heparin (activated clotting time, 1.5 normal) or acenocoumarol (international normalized ratio, 1.5-2.0; Ciba-Geigy, Rueil-Malmaison, France). After 1 month, the anticoagulation treatment was discontinued. Since 1998, the practice of postoperative anticoagulation for patients with a bioprosthesis has been discontinued, with the exception of those in atrial fibrillation (target international normalized ratio, 2-3). Antiplatelet agents were prescribed for cardiac (ischemic heart disease) or vascular (ischemic vascular accident, occlusive arterial disease of the lower limbs) indications only.

Because the present study involved only a retrospective medical record review and used only de-identified data, it qualified for exemption from institutional review board approval.

\section{Statistical Analysis}

Early events ( $\leq 30$ days after surgery) were calculated as simple percentages (number of complications divided by number of patients). Linearized rates for late events ( $>30$ days after surgery) represent the number of complications per 100 valve-years. Kaplan-Meier actuarial analyses, including both early and late events, are presented, with the Greenwood formula for the variance. Testing differences between $\geq 2$ survival curves was done using the log-rank or Mantel-Haenszel test. Each patient's life expectancy was calculated using the demographic life tables published by the French national demographic study institute (Institut national d'études démographiques). ${ }^{8}$ Life expectancy was dependent on patient age, year of surgery, and gender. Life expectancy and expected valve durability were estimated by the median survival time (MST) — the point at which the Kaplan-Meier curve crosses 0.5 probability, and with the restricted mean or area under the Kaplan-Meier curve (area under the curve [AUC]) - truncated with the latest available upper limit. Multivariate Cox proportional hazards regression analysis was used to identify the risk factors and estimate the hazard ratios (HRs) of the baseline hazard for mortality and valve deterioration. For nonfatal events, such as structural valve deterioration (SVD), competing risk analyses,,${ }^{9,10}$ often referred to as "actual" analyses in published studies, were performed using the R cmprsk package, version 2.13.1 (The R Project for Statistical Computing).

\section{RESULTS \\ Operative Mortality, Functional Status, and Survival Rates}

A total of 15 deaths were reported in the operative period, for a total operative mortality rate of $3.3 \%$.

The postoperative New York Heart Association functional class was available for all patients who were reported as alive with the valve in place at the last follow-up point $(n=156)$. Of these patients, $72 \%$ showed significant improvement from the preoperative score.

A total of 188 late deaths were recorded, for a linearized rate of $5.8 \%$ /valve-year. Of these, $40(1.2 \% /$ valve-year $)$ were designated as valve-related: thromboembolism in 5, hemorrhage in 4, endocarditis in 4, SVD in 4, and sudden death in 23.

At 20 years, the overall actuarial survival rate was $16.9 \%$ $\pm 3.9 \%$, and the valve-related actuarial survival rate was $62.4 \% \pm 9.0 \%$ (Figure 1). Patient age at implantation (HR, 1.06; $P<.001)$, New York Heart Association class III-IV (HR, 1.86; $P<.001$ ), and reoperation for SVD (HR, $1.51 ; P=.021)$ were significant risk factors affecting late survival.

All main events and early event rates, linearized rates, Kaplan-Meier estimates at 10, 15 and 20 years, and 2 freedom from event expectancy estimates (MST and AUC) are listed in Table 2.

\section{Valve-Related Complications}

Thromboembolic events. No case of valve thrombosis was reported.

A total of 23 thromboembolic events were reported, for a linearized rate of $0.7 \%$ /valve-year. Of these, 5 occurred during the first 30 postoperative days $(1.1 \%)$; 7 led to death and 4 to permanent neurologic deficit. Finally, 12 were considered minor, with the patient having a complete recovery. The 10-, 15-, and 20-year freedom from thromboembolism rate was $93.4 \% \pm 1.5 \%, 91.5 \% \pm 2.4 \%$, and $83.9 \%$ $\pm 7.6 \%$, respectively.

Bleeding events. A total of 27 bleeding events were reported (linearized rate, $0.8 \% /$ valve-year) and led to death for 4 patients. Of these, 22 occurred in the postoperative period, and 16 were related to the anticoagulant use. The mean age of the patients with bleeding events (66.6 years) was similar to that of the patients without events (68.1 years). During the follow-up period, $65 \%$ of the patients had used warfarin for anticoagulation, $75 \%$ of whom were reported to have atrial fibrillation or atrial flutter. For the others, anticoagulant agents were prescribed for cardiac (congestive heart failure), vascular arterial (ischemic 
TABLE 1. Patient demographics

\begin{tabular}{|c|c|}
\hline Variable & Value \\
\hline Mitral prostheses (n) & 450 \\
\hline Patients (n) & 404 \\
\hline \multicolumn{2}{|l|}{ Age (y) } \\
\hline Range & $22-89$ \\
\hline Mean \pm SD & $68.0 \pm 10.4$ \\
\hline \multicolumn{2}{|l|}{ Gender } \\
\hline Male & $210(46.7)$ \\
\hline Female & $240(53.3)$ \\
\hline \multicolumn{2}{|l|}{ Etiology } \\
\hline Degenerative & $160(35.6)$ \\
\hline Reoperative & $127(28.2)$ \\
\hline Rheumatic & $117(26.0)$ \\
\hline Ischemic & $26(5.8)$ \\
\hline Endocarditis & $20(4.4)$ \\
\hline \multicolumn{2}{|l|}{ Lesion } \\
\hline Regurgitation & 277 (61.6) \\
\hline Stenosis & $109(24.2)$ \\
\hline Mixed & $64(14.2)$ \\
\hline \multicolumn{2}{|l|}{ Preoperative NYHA } \\
\hline I & $56(12.4)$ \\
\hline II & $139(30.9)$ \\
\hline III & $156(34.7)$ \\
\hline IV & $99(22.0)$ \\
\hline Atrial fibrillation & $171(38.0)$ \\
\hline \multicolumn{2}{|l|}{ Preoperative LVEF (\%) } \\
\hline$>50$ & $415(92.2)$ \\
\hline $35-50$ & $30(6.8)$ \\
\hline $20-34$ & $4(0.8)$ \\
\hline$<20$ & $1(0.2)$ \\
\hline \multicolumn{2}{|l|}{ Valve size $(\mathrm{mm})$} \\
\hline 25 & $6(1.3)$ \\
\hline 27 & $166(36.9)$ \\
\hline 29 & 187 (41.6) \\
\hline 31 & $80(17.8)$ \\
\hline 33 & $11(2.4)$ \\
\hline Associated procedures & $193(42.9)$ \\
\hline CABG & $69(15.3)$ \\
\hline Operative mortality & $15(3.3)$ \\
\hline \multicolumn{2}{|l|}{ Follow-up (y) } \\
\hline Total, valve-year & 3257.8 \\
\hline Mean \pm SD & $7.2 \pm 5.1$ \\
\hline Range & $0-24.8$ \\
\hline Lost to follow-up & $10(2.2)$ \\
\hline
\end{tabular}

Data presented as $\mathrm{n}(\%)$ or mean $\pm \mathrm{SD}$ and range. $S D$, Standard deviation; $N Y H A$, New York Heart Association functional class; $L V E F$, left ventricular ejection fraction; $C A B G$, coronary artery bypass grafting.

vascular accident, occlusive arterial disease of the lower limbs), or venous (venous thrombosis, pulmonary embolism) indications. The 20-year actuarial freedom from anticoagulant-related hemorrhage was $80.2 \% \pm 10.8 \%$.

Operated valve endocarditis. Endocarditis was reported in 15 patients. Of these patients, 4 died without reoperation, 4 underwent reoperation, and 7 were successfully treated using antibiotics alone. The 20-year actuarial freedom from endocarditis was $94.8 \% \pm 1.4 \%$.

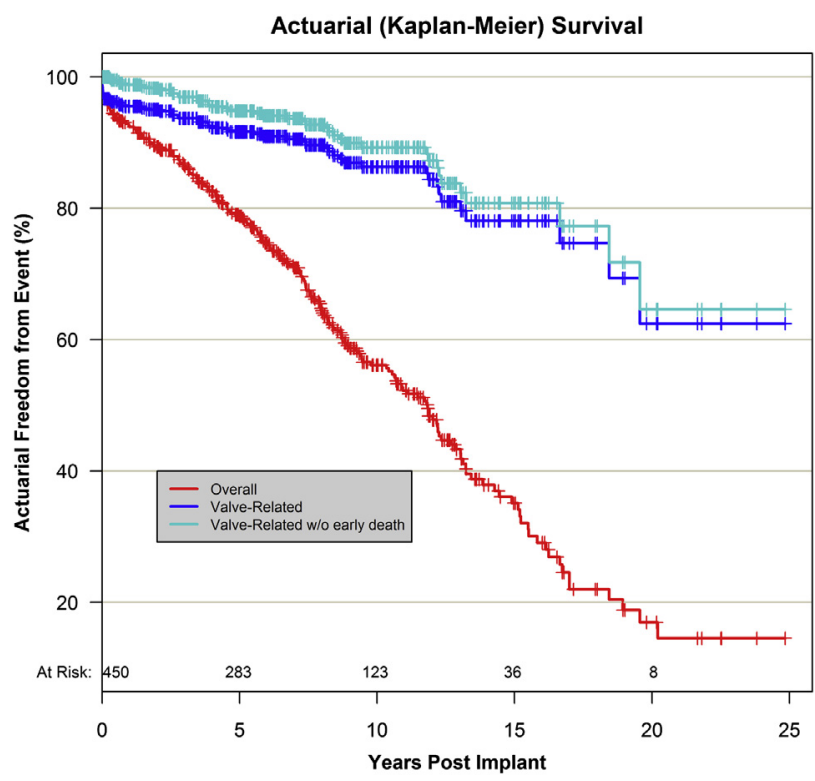

FIGURE 1. Kaplan-Meier estimates of overall and valve-related mortality.

Nonstructural dysfunction. No clinically significant hemolysis was recorded in the absence of structural valve dysfunction.

Structural valve deterioration. The mitral bioprosthesis was considered to have deteriorated on strict echocardiographic assessment when severe regurgitation (effective regurgitant orifice area $\geq 40 \mathrm{~mm}^{2}$ ) or stenosis (mean transvalvular gradient $>8 \mathrm{~mm} \mathrm{Hg}$ ) was observed, even if the patient was asymptomatic. SVD was reported in 76 patients $(2.3 \% / v a l v e-y e a r)$. Of these patients, 63 underwent reoperation, and 13 had died rapidly after SVD had been diagnosed. SVD had occurred because of excessive calcification in most cases $(76.3 \%)$, followed by leaflet tear $(19.7 \%)$, or both $(3.9 \%)$. The mean interval to the onset of SVD was significantly longer in the case of leaflet tear than for calcification $(14.8$ years; $95 \%$ confidence interval [CI], 12.7-16.9; and 10.1 years; 95\% CI, 9.2-11.0, respectively; $P<.001$ ).

The actuarial freedom from SVD at 20 years was $23.7 \%$ $\pm 6.9 \%$, and the actuarial freedom from explantation because of SVD at 20 years was $40.5 \% \pm 8.0 \%$. The expected valve durability, calculated by the MST from the actuarial freedom from SVD, was 16.6 years $(95 \% \mathrm{CI}$, 14.5-19.1). Patient age at implantation, with a HR of 0.96 (95\% CI, 0.94-0.97), was the only significant risk factor affecting SVD. No difference was observed for gender, valve size, etiology, or New York Heart Association classification.

To answer patients" often asked question: "What is the chance that a reoperation will be needed because of valve deterioration after a certain amount of time?", competing risk analysis was performed. Because the intervention has usually been performed late in the patient's life, the 
TABLE 2. Summary of main events-freedom from events with Kaplan-Meier estimates

\begin{tabular}{|c|c|c|c|c|c|c|c|}
\hline \multirow[b]{2}{*}{ Variable } & \multirow[b]{2}{*}{ Event rate $(\leq \mathbf{3 0} \mathbf{d})$} & \multirow[b]{2}{*}{ Linearized rate $(>30 \mathrm{~d})$} & \multicolumn{3}{|c|}{ Kaplan-Meier estimate (\%) } & \multirow[b]{2}{*}{$\operatorname{MST}(\mathbf{y})$} & \multirow[b]{2}{*}{$\operatorname{AUC}(\mathbf{y})$} \\
\hline & & & At $10 y$ & At $15 y$ & At $20 y$ & & \\
\hline Mortality & $15(3.3)$ & $188(5.8 \% / v y)$ & $56.1 \pm 2.8$ & $35.1 \pm 3.5$ & $16.9 \pm 3.9$ & 11.8 & 11.9 \\
\hline Valve-related mortality & $15(3.3)$ & $40(1.2 \% / v y)$ & $86.3 \pm 2.1$ & $78.1 \pm 3.5$ & $62.4 \pm 9.0$ & NA* & 20.0 \\
\hline Reoperation & $1(0.2)$ & $81(2.5 \% / v y)$ & $81.0 \pm 2.7$ & $57.6 \pm 4.3$ & $37.1 \pm 7.4$ & 16.8 & 16.6 \\
\hline Any complication & $12(2.7)$ & $133(4.1 \% / v y)$ & $63.5 \pm 3.1$ & $39.1 \pm 4.2$ & $11.4 \pm 4.9$ & 12.1 & 12.6 \\
\hline Operated valve endocarditis & $1(0.2)$ & $14(0.4 \% / v y)$ & $94.8 \pm 1.4$ & $94.8 \pm 1.4$ & $94.8 \pm 1.4$ & $\mathrm{NA}^{*}$ & 23.8 \\
\hline Thromboembolism & $5(1.1)$ & $18(0.6 \% / v y)$ & $93.4 \pm 1.5$ & $91.5 \pm 2.4$ & $83.9 \pm 7.6$ & $\mathrm{NA}^{*}$ & 22.8 \\
\hline Bleeding & $5(1.1)$ & $22(0.7 \% / v y)$ & $91.6 \pm 1.7$ & $91.6 \pm 1.7$ & $80.2 \pm 10.8$ & $\mathrm{NA}^{*}$ & 21.6 \\
\hline SVD & $0(0.0)$ & $76(2.3 \% / v y)$ & $83.9 \pm 2.7$ & $55.4 \pm 4.8$ & $23.7 \pm 6.9$ & 16.6 & 16.1 \\
\hline Explantation for SVD & $0(0.0)$ & $63(1.9 \% / v y)$ & $86.3 \pm 2.5$ & $62.8 \pm 4.5$ & $40.5 \pm 8.0$ & 19.0 & 17.5 \\
\hline
\end{tabular}

Data presented as n (\%), unless otherwise noted. $M S T$, Median survival time; $A U C$, area under the curve; $N A$, not applicable; $S V D$, structural valve deterioration. $*$ Survival curve did not cross 0.5 ; thus, the MST was not applicable.

probability of death, from cardiac or other causes, will be greater than the probability of reoperation for SVD (Figure E1). The cumulative risk of valve explantation owing to SVD at 15 and 20 years was $20.4 \% \pm 2.5 \%$ and $25.5 \% \pm 2.9 \%$, respectively, much lower than the corresponding actuarial estimates $(37.2 \% \pm 4.5 \%$ and $59.5 \%$ $\pm 8.0 \%$ ) and also lower than the corresponding probability of death $(57.5 \% \pm 3.0 \%$ and $67.7 \% \pm 3.2 \%)$.

SVD stratified by age group. The population was divided into different age groups at implantation for analysis of the actuarial SVD and reoperation because of SVD. For patients $<65$ years old, the freedom from SVD at 15 and 20 years was $47.3 \% \pm 6.5 \%$ and $19.1 \% \pm 7.0 \%$, with 19 and 5 patients at risk, respectively. For patients aged $\geq 65$ years, the corresponding estimates were $62.5 \% \pm 7.3 \%$ and $29.6 \% \pm 14.6 \%$, with 15 and 2 patients at risk, respectively. This difference was statistically significant $(P=.04)$. The valve durability for patients aged $<65$ years and those aged $\geq 65$ years was 14.2 and 18.9 years, respectively. The freedom from reoperation for SVD at 15 and 20 years was $49.5 \% \pm 6.4 \%$ and $25.1 \% \pm 7.5 \%$, respectively, for the younger group and $76.8 \% \pm 5.2 \%$ at 15 years for the older group, remaining constant thereafter.

Figure 2 displays the additional age groups for reoperation because of SVD $(\leq 60,61-70$, and $>70$ years $)$. The difference among the groups was highly significant $(P=.001)$, with an expected interval to reoperation for SVD of 11.9 and 19.0 years for patients aged $\leq 60$ years and 61 to 70 years, respectively. For patients aged 50 to 60 years at implantation, the expected valve durability remained $>15$ years ( 15.7 years) and the estimated time to requiring reoperation was $>16$ years (16.2 years). The results of competing risk regression analysis to evaluate the cumulative risk of reoperation for SVD with age as the unique covariate are shown in Figure 3. The corresponding HR was 0.93 (95\% CI, 0.91-0.94). The data were also computed to indicate the number of years a patient could expect before requiring reoperation for SVD depending on their age at implantation (Table 3).
Finally, we subdivided the cohort by age decile and displayed the sample life expectancy and expected valve durability relative to the life expectancy of the general population in France. ${ }^{8}$ Mitral valve disease and surgical valve replacement appeared to reduce life expectancy compared with that of the general population; however, this difference declined significantly as patient age at surgery increased. Except for the first decile of age at implantation (15-56 years), the expected valve durability estimate was greater than the life expectancy after MVR (Figure E2). Reoperation. A total of 82 reoperations were reported; 1 during the operative period because of severe aortic regurgitation and 81 in the postoperative period (linearized rate, $2.5 \%$ /valve-year). Eight mitral prostheses were explanted prophylactically during another cardiac operation: 6 aortic valve replacements, 1 coronary artery bypass grafting, and 1 tricuspid valve repair. Finally, 73 reoperations

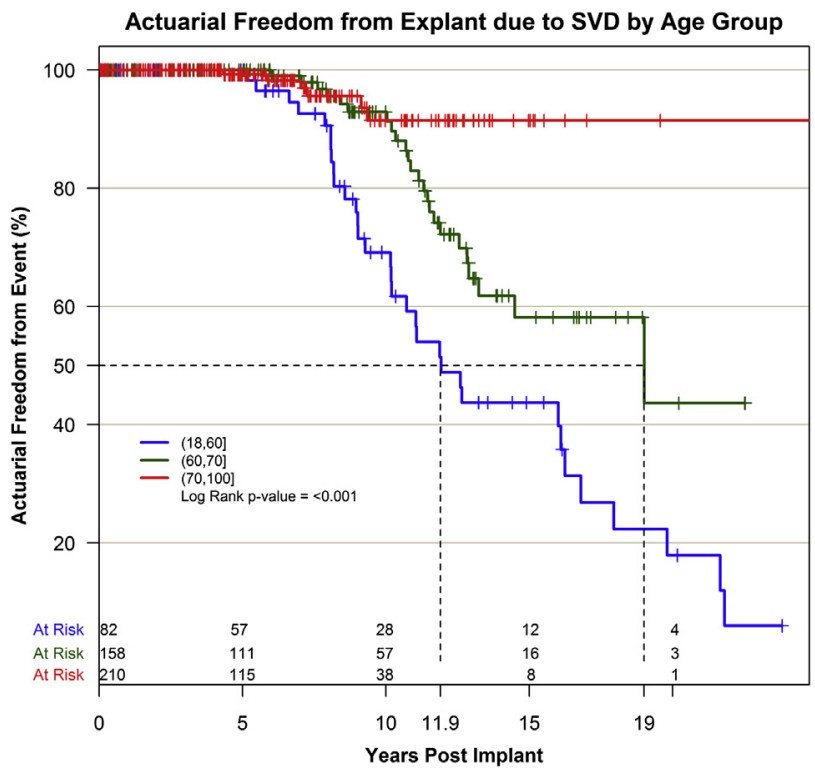

FIGURE 2. Kaplan-Meier estimates of explantation because of structural valve deterioration $(S V D)$ stratified by age group. 


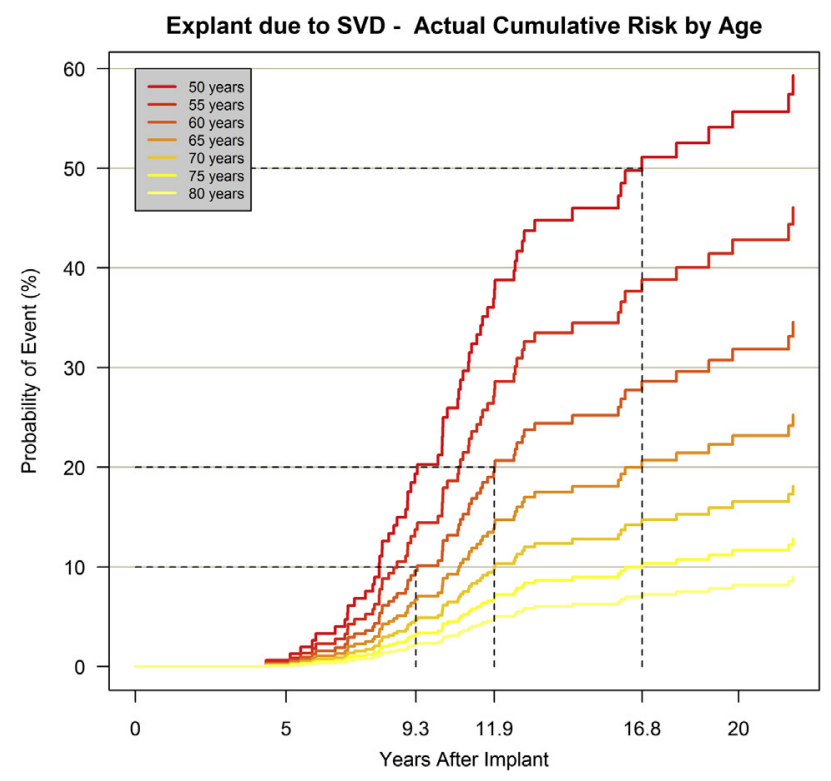

FIGURE 3. Competing risk estimates of explantation because of structural valve deterioration $(S V D)$ stratified by age group.

were valve-related: 63 because of SVD, 6 because of valve dehiscence, and 4 because of operated valve endocarditis. The 20-year actuarial freedom from valve explantation for all causes was $37.1 \% \pm 7.4 \%$.

\section{DISCUSSION}

In the present study, we evaluated the long-term durability of the Carpentier-Edwards PERIMOUNT pericardial bioprosthesis in the mitral position and report the longest term follow-up data with this prosthesis, with 8 patients at risk at 20 years and 1 at 24.8 years. Furthermore, to our knowledge, ours is the longest study in terms of total follow-up data, with $>3250$ valve-years in the mitral position. Our report also presents the patient's viewpoint: depending on patient age at surgery, we have estimated the risk and number of years before a reoperation would be required because of SVD.

\section{Survival}

In accordance with the guidelines, deaths from sudden or unknown causes were conservatively included in the valve-related category. In our experience, the overall survival rate was $16.9 \% \pm 3.9 \%$, and the freedom from valve-related mortality was $61.7 \% \pm 8.9 \%$ at 20 years. For the group treated from 1984 to 1991, who had followup data in 2011 for $\geq 20$ years, the life expectancy of a patient 70 years old in France was 11.2 to 12.3 years for men and 14.6 to 15.9 years for women. ${ }^{8}$ From our analyzed cohort, $50 \%$ of our patients were still alive at 11.8 years, and the AUC was 11.9 years. Therefore, the life expectancy after MVR was similar to the age- and gender-adjusted life expectancy for the general population. The valve-related life expectancy demonstrated an AUC of 19.8 years, much greater than the general population life expectancy. Analyzing the survival rates, it is noteworthy that one third of MVRs were for degenerative mitral valve disease. To understand this low repair rate, one should remember that our series has reported a 25-year experience and began when mitral valve repair was not yet the reference standard for degenerative mitral valve surgery.

\section{Expected Valve Durability (SVD, Reoperation for SVD)}

In the present study, SVD was determined strictly from the annual echocardiographic assessment. We reported 76 patients with SVD $(2.3 \%$ /valve-year $)$, of whom 63 underwent reoperation-all elective-with no operative mortality. The major consideration with a deteriorated bioprosthesis, as stated by McGiffin and colleagues, ${ }^{11}$ is "the competing risks of death without re-replacement and re-replacement before death." Jamieson and colleagues ${ }^{12}$ reported a mortality rate of $6.3 \%$ for isolated mitral valve repeat replacement. Only age at implantation and at explantation were significant risk factors for mortality. They concluded that the mortality rate after reoperation for SVD could be significantly reduced by optimizing the timing of surgery before the onset of advanced symptoms and emergency status. ${ }^{12}$ Consistent with these data, our good results concerning reoperations can be explained because patients with deteriorated mitral bioprostheses underwent reoperation, even if they were asymptomatic. More recently, Wilbring and colleagues ${ }^{13}$ reported very promising results with transapical mitral valve-in-valve

TABLE 3. Explantation for SVD stratified by age group-competing risk (actual) estimates

\begin{tabular}{lccccccc}
\hline & \multicolumn{7}{c}{ Age (y) } \\
\cline { 2 - 7 } Probability (\%) & $\mathbf{5 0}$ & $\mathbf{5 5}$ & $\mathbf{6 0}$ & $\mathbf{6 5}$ & $\mathbf{7 0}$ & $\mathbf{7 5}$ & $\mathbf{8 0}$ \\
\hline 5 & 7.0 & 7.6 & 8.1 & 8.7 & 10.0 & 10.8 \\
10 & 8.1 & 8.7 & 9.3 & 10.7 & 11.9 & 16.8 \\
15 & 9.0 & 10.0 & 10.9 & 12.6 & 17.9 & - \\
20 & 9.3 & 10.7 & 11.9 & 16.8 & - & - \\
25 & 10.3 & 11.5 & 14.5 & 21.8 & - & - \\
\hline
\end{tabular}

Data presented as interval to reoperation for SVD in years. A 60 -year-old patient would have a probability of $20 \%$ of requiring reoperation for SVD after 11.9 years, with the probability increasing $\leq 25 \%$ after 14.5 years. $S V D$, Structural valve deterioration. 
implantation for high-risk patients with bioprosthetic valve SVD. In deciding between mechanical and biologic mitral prostheses, the mortality associated with reoperation should be balanced against the risk of thromboembolic and hemorrhagic events associated with anticoagulants.

The results for SVD from our study revealed an overall actuarial freedom from SVD of $83.9 \% \pm 2.7 \%$ and $23.7 \% \pm 6.9 \%$ at 10 and 20 years, respectively. The expected valve durability remained satisfactory in the long term, with a MST of 16.6 years $(95 \%$ CI, 14.5-19.1) before valve deterioration. For the specific 50- to 60-year-old patient group, the expected valve durability remained $>15$ years (15.7 years). The freedom from reoperation for SVD was $86.3 \% \pm 2.5 \%$ and $40.5 \% \pm 8.0 \%$ at 10 and 20 years, respectively, with a MST of 19.0 years.

As recommended by Grunkemeier and colleagues ${ }^{9}$ and Rahimtoola $^{10}$ for the study of nonfatal events, we performed a competing risk "actual" analysis, in addition to the actuarial analyses. After 20 years, the competing risk analysis demonstrated that the probability of valve-related mortality was $18.1 \% \pm 2.4 \%$, reoperation for SVD was $25.4 \% \pm 2.9 \%$, and noncardiac mortality was $49.6 \% \pm$ $3.2 \%$. For patients aged $\geq 65$ years at implantation, the 20 -year actuarial risk of reoperation for SVD was $23.2 \%$ $\pm 5.2 \%$ and the cumulative incidence of reoperation for SVD was $11.5 \% \pm 2.5 \%$. For patients $>70$ years, the 20 -year actuarial risk and cumulative incidence of reoperation for SVD was $8.5 \% \pm 3.6 \%$ and $4.6 \% \pm 1.8 \%$, respectively.

When comparing the expected valve durability with the sample life expectancy after MVR for the different age groups, we demonstrated that the expected valve durability was greater, at least for $90 \%$ of the cohort (patients $>55$ years old at implantation).

Similar clinical outcomes at intermediate-term follow-up have been reported by others, using the same bioprosthesis. At 10 years after MVR, the overall freedom from SVD was $81 \%$ in the study by Poirier and colleagues ${ }^{14}$ and $77 \%$ in the study by Murakami and associates. ${ }^{15}$ In a previous study, we reported excellent intermediate-term outcomes with the Carpentier-Edwards PERIMOUNT pericardial prosthesis in the mitral position, ${ }^{7}$ in particular, regarding the lack of premature valve failure or leaflet tear. The 12-year freedom from SVD was $78 \%$ for all patients and was $100 \%$ for patients $>60$ years old at implantation.

No long-term results were found in published studies for other pericardial valves, in either the aortic or mitral position. The intermediate outcomes with the pericardial Sorin Pericarbon (Sorin Group, Milan, Italy) reported a 12-year freedom from SVD of $56.8 \% \pm 6.6 \%(86.3 \% \pm 7.5 \%$ in patients $>60$ years old and $36.8 \% \pm 8.2 \%$ in younger patients). ${ }^{16}$ The clinical performance of the Mitroflow pericardial bioprosthesis (Sorin Group) was even less satisfactory, with an 8-year freedom from SVD of $58 \% \pm 6 \%$. ${ }^{17}$
The durability of the Carpentier-Edwards PERIMOUNT bioprosthesis also compared favorably with the newgeneration porcine valves. ${ }^{18,19}$ David and colleagues ${ }^{20}$ reported a 12 -year freedom from SVD of $82 \% \pm 5 \%$ with the Hancock II mitral porcine bioprosthesis (Medtronic, Parsippany-Troy Hills, NJ) for patients with a mean age of 65 years. Jamieson and colleagues ${ }^{21}$ compared the secondgeneration Carpentier-Edwards Supra-Annular porcine valve to the Carpentier-Edwards PERIMOUNT bioprosthesis. They found that, at 10 years, the freedom from SVD was lower for the Carpentier-Edwards Supra-Annular porcine valve $(64.7 \% \pm 3.3 \%$ vs $84.0 \% \pm 3.7 \%$ for the PERIMOUNT in patients aged $\leq 60$ years and $75.2 \% \pm$ $3.7 \%$ vs $95.2 \% \pm 2.1 \%$ for the PERIMOUNT in patients aged 61-70 years). The direct relationship between age at implantation and bioprosthetic valve durability was especially pronounced. Comparing the durability of the CarpentierEdwards PERIMOUNT pericardial versus porcine bioprosthesis, Grunkemeier and colleagues ${ }^{22}$ reported a rate of reoperation for SVD of $16 \% \pm 3.3 \%$ at 15 years for the porcine versus $5 \% \pm 3.2 \%$ at 8 years for the pericardial valves $(P=.13)$. Despite the shorter follow-up period for the pericardial cohort, these investigators concluded that a pericardial valve protected against reoperation for SVD in the mitral position (HR, $0.39 ; P=.08) .{ }^{22}$ Patient age at valve implantation is a major determinant of life expectancy, risk of bleeding with anticoagulation treatment, ${ }^{23}$ and valve durability. Similar to other studies, ${ }^{18,24,25}$ we found a significant relationship between patient age at implantation and the risk of reoperation for SVD.

\section{Biologic Versus Mechanical}

When considering MVR, the appropriate choice between a mechanical and bioprosthetic valve will often be unclear. The patient's age, need for long-term anticoagulation, and existence of comorbidities are all important considerations in choosing the best valve for the individual patient.

Direct comparisons of adverse event rates between mechanical and bioprosthetic valves have often been difficult, because the mean age of mechanical valve recipients has tended to be significantly younger than that of patients receiving bioprostheses. Holper and colleagues ${ }^{26}$ reported on a cohort of patients aged $\geq 65$ years who had undergone isolated valve replacement with a mechanical or bioprosthetic valve and reported no difference in thromboembolic rates. However, their reported thromboembolic event-free survival rate for mechanical valves $(86 \% \pm$ $6 \%$ at 15 years) was lower than that in our experience $(91.5 \% \pm 2.4 \%$ at 15 years and $83.9 \% \pm 7.6 \%$ at 20 years; linearized rate, $0.6 \%$ /valve-year). More precisely, concerning thromboembolic complications after mitral valve surgery, Russo and colleagues ${ }^{27}$ found that the ischemic stroke rate at 5 years after MVR with a bioprosthesis was slightly greater than that after mitral valve repair but was 
divided by 2 compared with that for mechanical valves $(8 \%$ $\pm 2.1 \%$ vs $6.1 \% \pm 0.9 \%$ and $16.1 \% \pm 2.7 \%$, respectively; $P<.001)$.

Cannegieter and colleagues ${ }^{28}$ studied a cohort of patients receiving oral anticoagulation for mechanical valves $(30 \%$ mitral) and reported a bleeding event rate of 3.1\%/patientyear for women and $2.4 \%$ /patient-year for men. This was relatively consistent across the age groups, except for patients aged $\geq 70$ years, for whom the risk of bleeding was twice as high (5.6\%/patient-year). Holper and colleagues ${ }^{26}$ reported a 15-year actuarial freedom from hemorrhage of $88 \% \pm 4 \%$ with a bioprosthesis and $57 \% \pm 11 \%$ with a mechanical valve. In the present study, despite the relatively large number of patients $(65 \%)$ who received oral anticoagulation, the rate of major bleeding $(0.7 \%$ /valve-year; 20 -year actuarial freedom, $80.2 \% \pm 10.8 \%$ ) was lower than that observed in patients receiving a mechanical prosthesis. ${ }^{26,29,30}$ This could be explained by the different international normalized ratio targets: 2 to 3 for a bioprosthesis with atrial fibrillation compared with 3 to 4.5 for mechanical valves.

\section{Study Limitations}

The present study had a number of limitations. It was a retrospective study at a single center. The mean age of the population (68 \pm 10.4 years; range, 22-89) was relatively high compared with that in other published series $(60.7 \pm$ 11.6 years for Marchand and colleagues, ${ }^{4} 63.9 \pm 11.5$ years for Neville and colleagues ${ }^{7}$ ), which can be explained by the increasing age of patients referred for mitral surgery. The group of patients $<60$ years old at implantation was a selected group, for which we chose to use a bioprosthesis. The present study also had a performance bias, because all patients were not treated by the same surgeon. The mode of follow-up by questionnaire also introduced a risk of ascertainment bias. However, very few patients were lost to follow-up $(2.2 \%)$, and the maximum follow-up period was 24.8 years. Cardiologic follow-up data were ensured by the office cardiologists for most patients, although the observations were, therefore, performed by various physicians. However, all events were reported as occurring before or after 30 days, in strict compliance with American and European guidelines.

\section{CONCLUSIONS}

With a low rate of valve-related events at 20 years and, in particular, a low rate of SVD, the Carpentier-Edwards PERIMOUNT pericardial bioprosthesis remains a reliable choice for a tissue valve in the mitral position, especially in patients $>60$ years old.

\section{References}

1. Walley VM, Keon WJ. Patterns of failure in Ionescu-Shiley bovine pericardial bioprosthetic valves. J Thorac Cardiovasc Surg. 1987;93:925-33.
2. Trowbridge EA, Lawford PV, Crofts CE, Roberts KM. Pericardial heterografts: why do these valves fail? J Thorac Cardiovasc Surg. 1988;95:577-8.

3. Marchand M, Aupart MR, Norton R, Goldsmith IR, Pelletier C, Pellerin M, et al. Twelve-year experience with Carpentier-Edwards PERIMOUNT pericardial valve in the mitral position: a multicenter study. J Heart Valve Dis. 1998;7:292-8.

4. Marchand M, Aupart MR, Norton R, Goldsmith IR, Pelletier LC, Pellerin M, et al. Fifteen-year experience with the mitral Carpentier-Edwards PERIMOUNT pericardial bioprosthesis. Ann Thorac Surg. 2001;71:236-9.

5. Edmunds LH, Clarke RE, Cohn LH, Grunkemeier GL, Miller DC, Weisel RD. Guidelines for reporting morbidity and mortality after cardiac operations. The American Association for Thoracic Surgery, Ad Hoc Liaison Committee for standardizing Definitions of Prosthetic Heart Valve Morbidity. Ann Thorac Surg. 1996;62:932-5.

6. Akins CW, Miller DC, Turina MI, Kouchoukos NT, Blackstone EH, Grunkemeier GL, et al. Guidelines for reporting morbidity and mortality after cardiac valve interventions. J Thorac Cardiovasc Surg. 2008;135:732-8.

7. Neville PH, Aupart MR, Diemont FF, Sirinelli AL, Lemoine EM, Marchand MA. Carpentier-Edwards pericardial bioprosthesis in aortic or mitral position: a 12-year experience. Ann Thorac Surg. 1998;66:143-7.

8. National Institute of Statistics and Economic Studies, Demographic Situation. Life table 2009-2011. http://www.ined.fr/en/pop_figures/france/deaths_causes_ mortality/mortality_tables. Accessed March 11, 2014.

9. Grunkemeier GL, Jamieson WRE, Miller DG, Starr A. Actuarial vs. actual risk of porcine structural valve deterioration. J Thorac Cardiovasc Surg. 1994;108:709-18.

10. Rahimtoola SH. Choice of prosthetic heart valve in adults: an update. J Am Coll Cardiol. 2010;55:2413-26.

11. McGiffin DC, Galbraith AJ, O'Brien MF, McLachlan GJ, Naftel DC, Adams P, et al. An analysis of valve re-replacement after aortic valve replacement with biologic devices. J Thorac Cardiovasc Surg. 1997;113:311-8.

12. Jamieson WRE, Burr LH, Miyagishima RT, Janusz MT, Fradet GJ, Lichtenstein SV, et al. Reoperation for bioprosthetic mitral structural failure: risk assessment. Circulation. 2003;108:98-102.

13. Wilbring M, Alexiou K, Tugtekin SM, Sill B, Hammer P, Schmidt T, et al. Transapical transcatheter valve-in-valve implantation for deteriorated mitral valve bioprostheses. Ann Thorac Surg. 2013;95:111-7.

14. Poirier NC, Pelletier LC, Pellerin M, Carrier M. 15-Year experience with the Carpentier-Edwards pericardial bioprosthesis. Ann Thorac Surg. 1998;66:57-61.

15. Murakami T, Eishi K, Nakano S, Kobayashi J, Sasako Y, Isobe F, et al. Aortic and mitral valve replacement with the Carpentier-Edwards pericardial bioprosthesis: 10-year results. J Heart Valve Dis. 1996;5:45-9.

16. Caimmi PP, Di Summa M, Galloni M, Gastaldi L, Papillo B, Actis Dato GM, et al. Twelve-year follow up with the Sorin Pericarbon bioprosthesis in the mitral position. J Heart Valve Dis. 1998;7:400-6.

17. Pomar JL, Jamieson WRE, Pelletier LC, Gerein AN, Castellá M, Brownlee RT. Mitroflow pericardial bioprosthesis: clinical performance to ten years. Ann Thorac Surg. 1995;60:305-10.

18. Myken PS, Bech-Hansen O. A 20-year experience of 1712 patients with Biocor porcine bioprosthesis. J Thorac Cardiovasc Surg. 2009;137:76-81.

19. Valfré C, Ius P, Minniti G, Salvador L, Bottio T, Cesari F, et al. The fate of Hancock II porcine valve recipients 25 years after implant. Eur J Cardiothorac Surg. 2010;38:141-6.

20. David TE, Armstrong S, Sun Z. The Hancock II bioprosthesis at 12 years. Ann Thorac Surg. 1998;66:95-8.

21. Jamieson WRE, Marchand MA, Pelletier CL, Norton R, Pellerin M, Dubiel TW, et al. Structural valve deterioration in mitral replacement surgery: comparison of Carpentier-Edwards supra-annular porcine and PERIMOUNT pericardial bioprostheses. J Thorac Cardiovasc Surg. 1999;118:297-305.

22. Grunkemeier GL, Furnary AP, Wu Y, Wang L, Starr A. Durability of pericardial versus porcine bioprosthetic heart valves. J Thorac Cardiovasc Surg. 2012;144: 1381-6.

23. Palaretti G, Cosmi B. Bleeding with anticoagulation therapy: who is at risk and how best to identify such patients. Thromb Haemost. 2009;102:268-78.

24. Hammermeister KE, Sethi GK, Henderson WC, Grover FL, Oprian C, Rahimtoola SH. Outcomes 15 years after valve replacement with a mechanical versus bioprosthetic valve: final report of the Veterans Affairs randomized trial. J Am Coll Cardiol. 2000;36:1152-8.

25. Borger MA, Ivanov J, Armstrong S, Christie-Hrybinsky D, Feindel CM, David TE. Twenty-year results of the Hancock II bioprosthesis. J Heart Valv Dis. 2006;15:49-56.

26. Holper K, Wottke M, Lewe T, Baumer L, Meisner H, Paek SU, et al. Bioprosthetic and mechanical valves in the elderly: benefits and risks. Ann Thorac Surg. 1995;60:443-6. 
27. Russo A, Grigioni F, Avierinos JF, Freeman WK, Suri R, Michelena H, et al. Thromboembolic complications after surgical correction of mitral regurgitation incidence, predictors, and clinical implications. J Am Coll Cardiol. 2008;51: 1203-11.

28. Cannegieter SC, Rosendaal FR, Wintzen AR, Van der Meer FJM, Vandenbroucke JP, Briet E. Optimal oral anticoagulant therapy in patients with mechanical heart valves. N Engl J Med. 1995;333:11-7.
29. Horstkotte D, Schulte H, Bircks W, Strauer B. Unexpected findings concerning thromboembolic complications and anticoagulation after complete 10-year follow-up of patients with St. Jude Medical prostheses. J Heart Valve Dis 1993;2:291-301.

30. Toole JM, Stroud MR, Kratz JM, Crumbley AJ III, Bradley SM, Crawford FA Jr. Twenty-five year experience with the St. Jude medical mechanical valve prosthesis. Ann Thorac Surg. 2010;89:1402-9. 


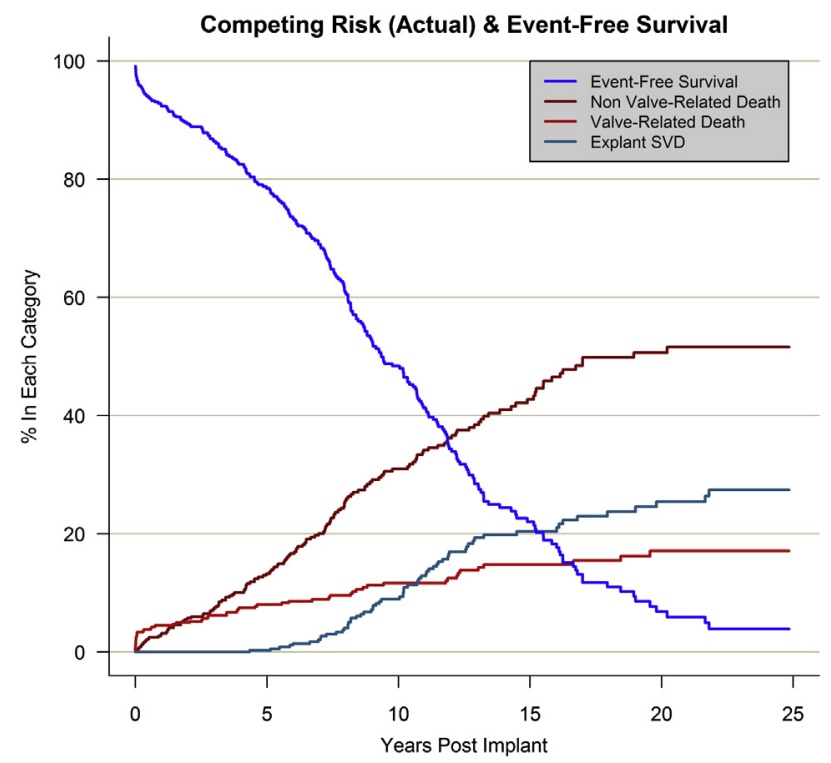

FIGURE E1. Competing risk analysis of explantation because of structural valve deterioration $(S V D)$.

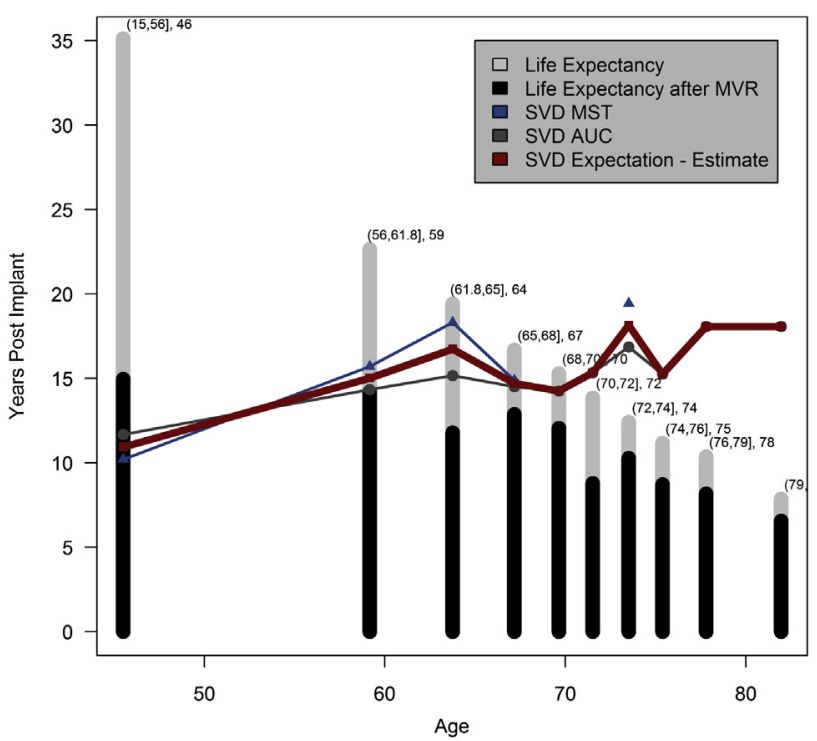

FIGURE E2. Valve durability and life expectation by age deciles. MVR, Mitral valve replacement; $M S T$, median survival time; $A U C$, area under the curve; $S V D$, structural valve deterioration. 